\title{
Understanding milling induced changes: Some results ${ }^{\text {II }}$
}

\author{
K CHATTOPADHYAY ${ }^{1,2}$, N RAVISHANKAR $^{2}$, T A ABINANDANAN $^{1}$ \\ and VIJI VARGHESE ${ }^{1 *}$ \\ ${ }^{1}$ Department of Metallurgy, and ${ }^{2}$ Materials Research Centre, Indian Institute \\ of Science, Bangalore 560 012, India \\ e-mail: kamanio@metalrg.iisc.ernet.in
}

\begin{abstract}
The effect of mechanical milling on materials has been studied using simple model systems. The results show that milling leads to enhancement in both thermodynamic driving force and transport kinetics. A study of some characteristic physical properties of the milled samples in comparison to the bulk shows how milling affects the properties.
\end{abstract}

Keywords. Mechanical milling; driven systems; mechanochemistry.

\section{Introduction}

Milling is identified as one of the robust processing routes for synthesizing a variety of materials. Commonly applied to the materials in solid state, the most noticeable change with milling is the reduction in the particle size, generally to nanoscale. In addition to size refinement, milling has received wide acceptability due to its potential to drive the changes at ambient conditions which are either not possible or require vigorous conditions in conventional processing routes. ${ }^{1-3}$ For example, while unfavourable decomposition steps restrict the high temperature chemical reactions of a number of materials, they can be easily brought about through milling at room temperature itself. ${ }^{4}$ Similarly, while the solubility of materials restricts the use of solution chemistry for synthesis, milling bypasses such limitations. ${ }^{5,6}$ The versatility and broad area of applicability of this technique are evident not only in chemical reactions, but also in changes such as phase transitions, alloying and amorphization. ${ }^{2,3}$ Thus, although the effect is known through antiquity, ${ }^{7}$ there has been a resurgence of interest in recent times.

Solutions to many of the processing problems encountered in mechanical alloying and mechanochemical reactions require basic understanding of the processes that take place with input of mechanical energy at rapid rates. These include the mechanism by which the changes take place, the influence of milling in deciding the direction and kinetics of the change, and the characteristics of the resultant product. In recent times, we have been carrying out an experiment-based programme of study using simple systems in order to understand the basic processes associated with the mechanical milling of solids ${ }^{8-15} \mathrm{We}$ show that milling leads to enhancement in the thermodynamic driving force as well as the transport kinetics. Also, we demonstrate the characteristic physical properties of the milled product in comparison to the bulk. A brief summary of the salient results obtained through this effort is presented in this article.

\footnotetext{
IDedicated to Professor C N R Rao on his 70th birthday

*For correspondence
} 


\section{Thermodynamic driving force in milling induced changes}

Thermodynamics plays a major role in the selection of phases. This is most striking if the phase is a new metastable phase not existing in the equilibrium phase diagram. A clear illustration of its importance is the effect of milling on $\mathrm{Ag}-\mathrm{Te}$ system at room temperature. ${ }^{10}$ It is known that rapid solidification of Te rich alloys yields a simple cubic phase with an $\alpha$ Po structure. ${ }^{16}$ Te undergoes transformation at high pressure to both the $\alpha \mathrm{Po}$ and the $\beta$ Po structures for which data on change in modulus are available. ${ }^{17}$ Figure 1 shows the computed free energy curves of these two possible metastable phases together with the equilibrium phases and a possible amorphous phase. A straight line between the free energies of $\mathrm{Ag}$ and Te gives the free energy of the mechanical mixture. However, the contribution from an increased area of grain boundaries raises the free energy curve of nanosized $(20 \mathrm{~nm})$ elemental mixtures of $\mathrm{Ag}$ and Te phases significantly. As a result, a large driving force develops for the formation of the metastable $\alpha$ Po structure. The experimental X-ray diffraction patterns of the samples milled for different times in a planetary mill are shown in figure 2 . The emergence of the simple cubic phase at the later stages of milling when the grain sizes reaches nanometric size is consistent with the thermodynamic prediction.

The actual physical mechanism for the grain size reduction differs for ductile and brittle materials. ${ }^{18,19}$ However, in all cases, the increase in the surface area leads to a

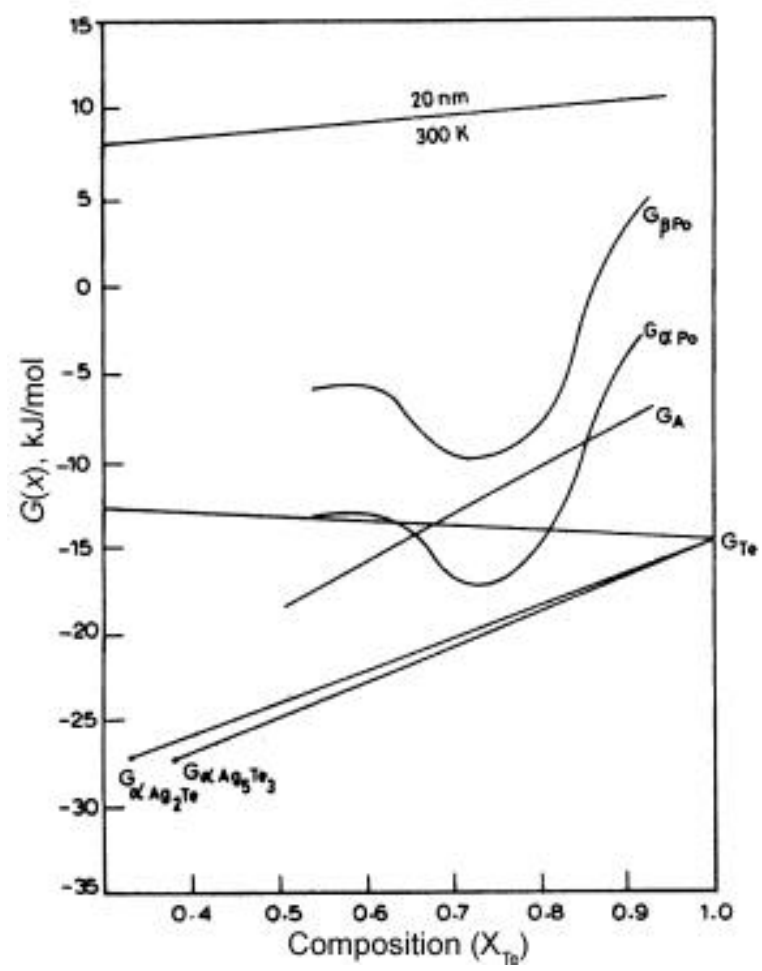

Figure 1. Free energy curves of the Ag-Te system at room temperature including the metastable phases. 


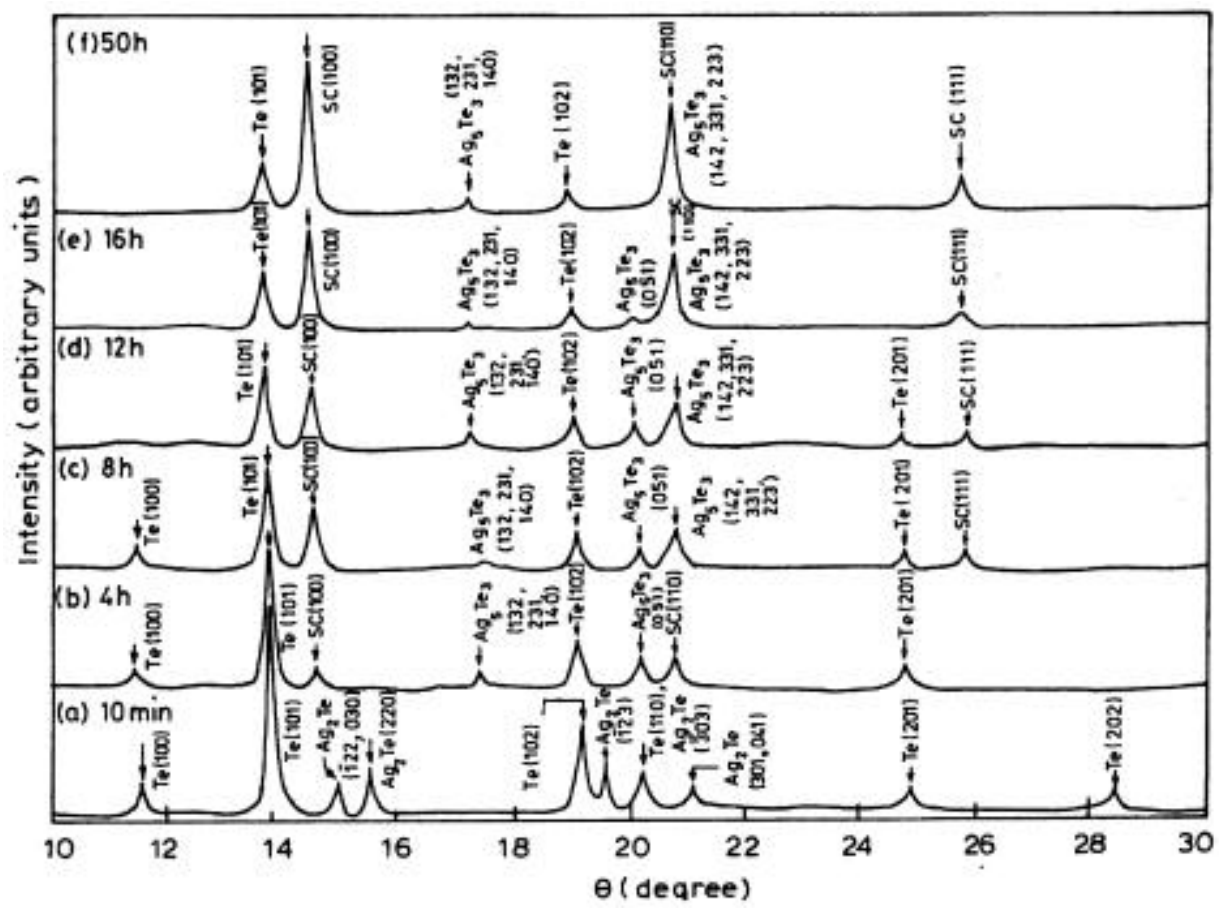

Figure 2. X-ray diffraction patterns of $\mathrm{Ag}-\mathrm{Te}$ system as a function of milling time showing the evolution of the simple cubic phase.

positive contribution to the free energy through an additional surface energy component. The question is, whether it is sufficient enough to change the free energy to effect the phase changes at the ambient temperature, specially, the changes like alloying in immiscible systems. ${ }^{2,3}$ Our experimental results on the ball milling of the binary immiscible $\mathrm{Fe}-\mathrm{Cu}$ powders to obtain a single phase solid solution provides an insight. ${ }^{11,20}$ Figure 3 shows a series of X-ray patterns of $\mathrm{Fe} 20 \% \mathrm{Cu}$ powder mixture in a planetary ball mill at different milling times depicting the evolution of the metastable solid solution. Figures $4 \mathrm{a}$ and $\mathrm{b}$ show the change in lattice parameter and grain size as a function of the milling time. The grain size reaches a minimum at about $12 \mathrm{~h}$ of milling. Interestingly, the lattice parameter continues to change with milling even when there is no significant change in the grain size. The change in lattice strain also exhibits a similar trend. If the contributions from both grain size and strain alone were responsible for enough change in thermodynamic driving force for the formation of the metastable solid solution, then, the change in lattice parameter would have followed the same trend as that of the grain size. And the process of formation of the solid solution should have been over by the time the grain size had attained its minimum. Evidently, our results suggest that the attainment of the minimum possible grain size is only the beginning of the process of alloying and formation of the solid solution. Thus, the refinement of grain size is not the only process which influences a milling induced transformation.

At this point one might ask the question, 'Can the mechanical energy alter the driving force such that a change which is otherwise not possible would occur?' A competing 
dynamics (CD) model, based on Martin's model for driven systems, ${ }^{21}$ along with an effective potential formalism was used to explain the phase stability under milling. ${ }^{12}$ The competing dynamics model considers the process as a competition between mixing (through milling) and demixing (thermal). The difference in the phase stability calculated under irradiation or mechanical alloying from that of the thermal equilibrium bulk stability leads to the modification of the phase diagram for driven alloys. We tried to extend this formalism with a reasonable estimate of the ballistic diffusivity and modified effective potential during the process. ${ }^{12}$ The phase diagram thus obtained is critically compared against the reported experimental results. The model in short can be described as follows.

The effective potential $\Phi$ is,

$$
\Phi=G+K
$$

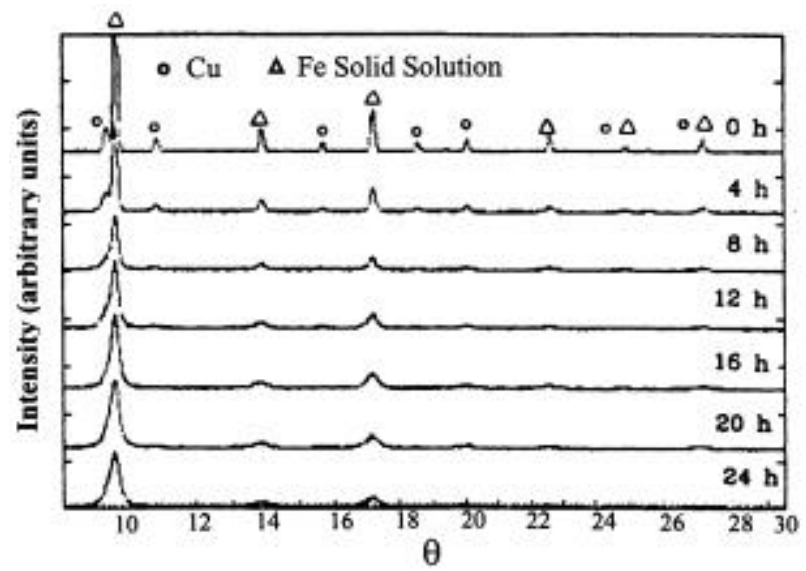

Figure 3. X-ray diffraction patterns of mechanically alloyed $\mathrm{Fe}-20 \% \mathrm{Cu}$ powders milled at room temperature for different times.
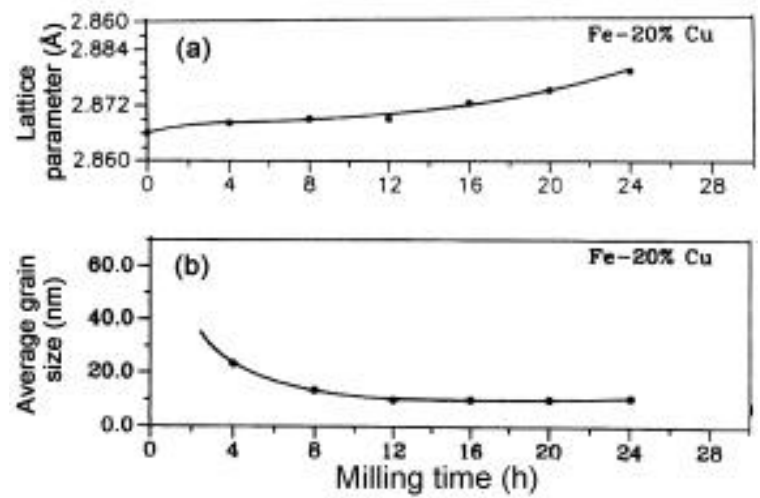

Figure 4. Plots showing changes in (a) lattice parameter, (b) grain size as a function of the milling time. 
where, $G$ is the Gibbs free energy and $K$ is ballistic potential

$$
K \quad \delta^{2} K / \delta x^{2}=D^{b} / M=\frac{x D_{A}^{b}+(1-x) D_{B}^{b}}{x(1-x)\left[x M_{A}+(1-x) M_{B}\right]},
$$

where $D^{b}$ is the ballistic diffusivity and $M$ is the mobility.

If $K_{A}$ and $K_{B}$ are the partial molar ballistic potentials, then,

$$
K=(1-x) K_{A}+x K_{B},
$$

and the Gibbs-Duhem equation would be

$$
x \mathrm{~d} K_{B}+(1-x) \mathrm{d} K_{A}=0,
$$

if we assume $D_{A}^{b}=D_{B}^{b}=D^{b}$ and the integration constants as zero, then the overall potential could be expressed as,

$$
\Phi=G+\frac{(1-x) D^{b}}{M_{A}} \ln \frac{(1-x)}{x M_{A}+(1-x) M_{B}}+\frac{x D^{b}}{M_{B}} \ln \frac{x}{x M_{A}+(1-x) M_{B}} .
$$

The dynamical phase diagram obtained for the binary system $\mathrm{Ag}-\mathrm{Cu}$ using the $\mathrm{CD}$ model with a calculated ballistic diffusivity $\left(10^{-22} \mathrm{~m}^{2} \mathrm{~s}^{-1}\right)$ is given in figure 5 . The striking feature of the phase diagram is the self closing miscibility gap at low temperature. Also it is seen that the low temperature miscibility increases with increasing ballistic diffusivity. Uneishi et $a l^{22}$ demonstrated complete solid solubility in mechanically milled $\mathrm{Ag}-\mathrm{Cu}$ alloys at room temperature. Later Herr and Samwer ${ }^{23}$ showed that samples milled at 383 and $423 \mathrm{~K}$ exist as a mixture of two phases even after prolonged milling. Thus the trend predicted by $\mathrm{CD}$ model is consistent with the experimental observation. Between the two competing factors, milling becomes the deciding parameter for the stability of phases when the contribution from demixing (thermal) becomes insignificant at low temperature compared to that from mixing (ballistic).

\section{Kinetics in milling aided changes}

In principle, the input of mechanical energy can affect the bonding within the system and thereby the kinetics of the process apart from the thermodynamic driving force. No

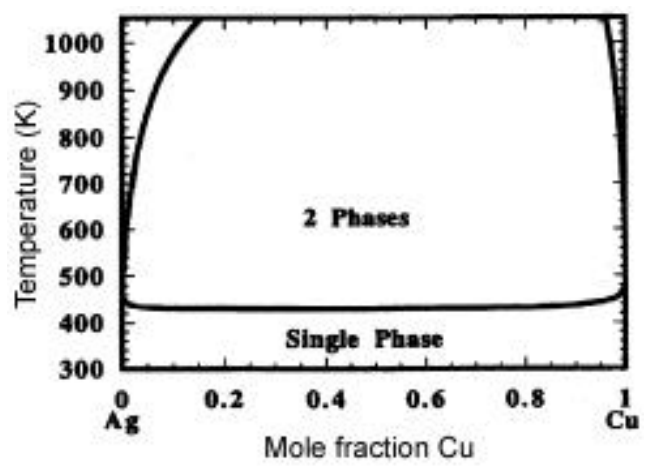

Figure 5. Dynamical phase diagram of $\mathrm{Ag}-\mathrm{Cu}$ system. 
systematic study on this aspect is available in the literature. In order to understand the factors influencing the kinetics in milling induced changes, the displacement of copper through different methods by different metals from copper sulphate in different forms have been selected as model reactions. ${ }^{13}$

In the solid state copper sulphate crystallizes with varying water of crystallization and $\mathrm{CuSO}_{4} .5 \mathrm{H}_{2} \mathrm{O}$ is the most common of all. A physical mixture of $\mathrm{Fe}$ and $\mathrm{CuSO}_{4} .5 \mathrm{H}_{2} \mathrm{O}$ does not promote the displacement of copper both at ambient and higher temperatures though the driving force does exist for the change. However, the reaction proceeded to certain extent at room temperature when a piece of $\mathrm{Fe}$ was immersed inside $\mathrm{CuSO}_{4} .5 \mathrm{H}_{2} \mathrm{O}$ and compacted (figure 6). While the reaction possibly did not progress much into the bulk in compaction route, the displacement of $\mathrm{Cu}$ in $\mathrm{CuSO}_{4} \cdot 5 \mathrm{H}_{2} \mathrm{O}$ and $\mathrm{Fe}$ mixture was complete within few hours when it is subjected to milling (figure 7). The size of reactant particles, proper mixing and intimate contact between reactants become quite important while the overall conversion in bulk is considered. Milling enhances both mixing and size reduction and provides intimate interface in each collision momentarily. Though, the amount of reaction mixture experiencing a single collision is small, the entire reaction mass would have undergone collision over a period of time due to the dynamic nature of the process yielding a bulk product.

Although the reduced diffusion length and dynamic nature of process end up in faster conversion in bulk, the factors contributing to faster reaction and diffusion also come into picture when the process is looked at microscopic level. Both milling and system characteristics play significant roles in deciding the rate of reaction as well as the mass transport. Over a period of milling it is reflected in the over all kinetics of the change.

The thermal analysis of milled $\mathrm{CuSO}_{4} \cdot 5 \mathrm{H}_{2} \mathrm{O}$ showed significant deviation from as obtained sample including additional weight loss step suggesting weakening in the bonding. The weakening in the bond strength can lead to enhancement in reaction rate. Apart

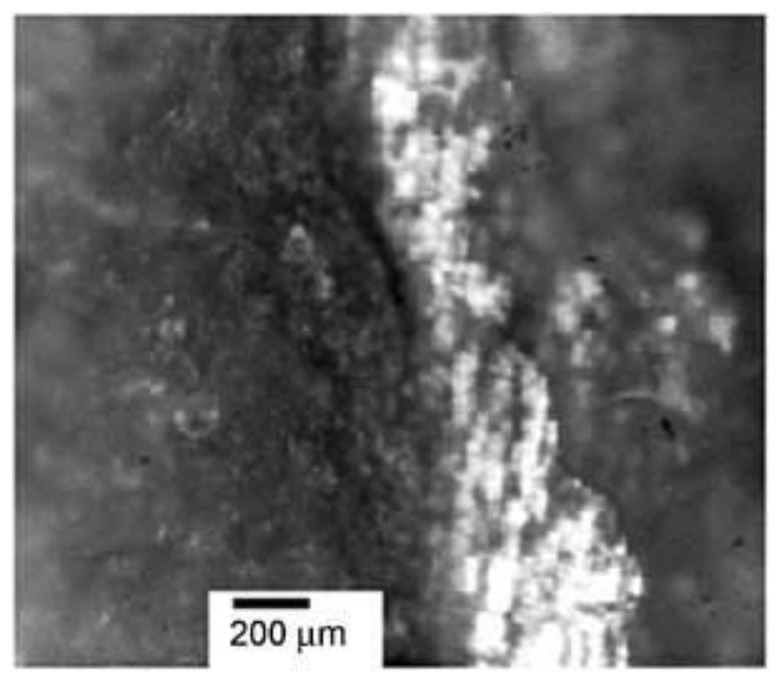

Figure 6. Optical micrograph of $\mathrm{Fe}-\mathrm{CuSO}_{4} \cdot 5 \mathrm{H}_{2} \mathrm{O}$ system, pressed at $150 \mathrm{MPa}$. A strip of $\mathrm{Fe}$ was kept between layers of $\mathrm{CuSO}_{4} \cdot 5 \mathrm{H}_{2} \mathrm{O}$ tiny crystals and pressed. $\mathrm{Cu}$ deposition can be seen. 


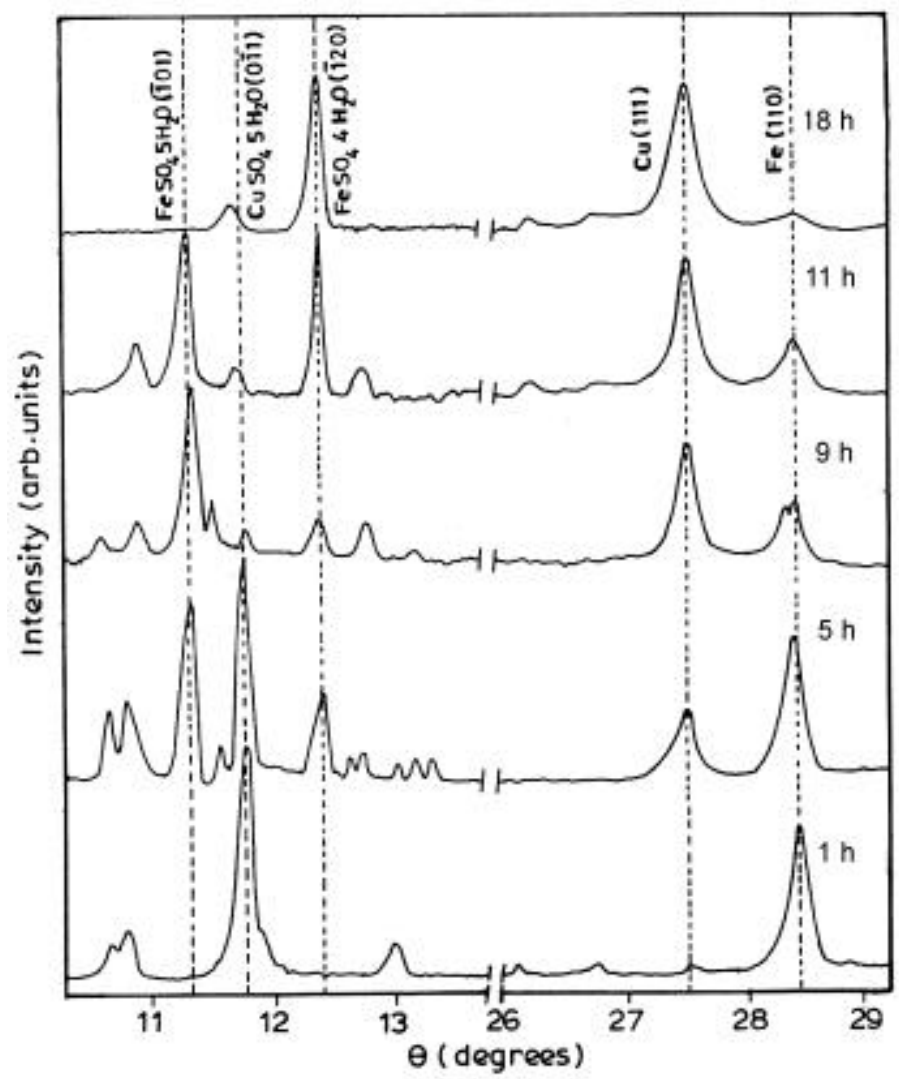

Figure 7. A series of X-ray diffraction patterns as a function of milling time showing the progress of mechanochemical reaction in the solid mixture of $\mathrm{Fe}$ and $\mathrm{CuSO}_{4} .5 \mathrm{H}_{2} \mathrm{O}$. The most intense reflection of reactants, intermediate and products are marked.

from affecting bonds, milling also introduces all types of defects leading to substantial size reduction. The presence of high concentration of defects and increased surface area promotes reaction rate as well as diffusion. The presence of pressure gradient generated at the time of collision can also contribute to the process.

The extent to which these will influence the kinetics depends on the nature of the system as well. Figure 8 shows that while copper was liberated progressively with milling, the phase jurbanite, $\left(\mathrm{Al}\left(\mathrm{SO}_{4}\right)(\mathrm{OH}) .5 \mathrm{H}_{2} \mathrm{O}\right)$ emerged as the end sulphate product in $\mathrm{CuSO}_{4} .5 \mathrm{H}_{2} \mathrm{O}-\mathrm{Al}$ system. ${ }^{14}$ Interestingly, the reaction was not faster compared to the reaction in $\mathrm{CuSO}_{4} .5 \mathrm{H}_{2} \mathrm{O}-\mathrm{Fe}$ though the driving force is much larger. Additionally, the absence of the expected end product $\mathrm{Al}_{2}\left(\mathrm{SO}_{4}\right)_{3} \cdot x \mathrm{H}_{2} \mathrm{O}$ in any stage of the reaction clearly brings out the difficulty in simultaneous electron transfer from three copper ions to two aluminium ions along with simultaneous ion rearrangements within the crystal to form a completely different molecular structure for the product sulphate. Thus in $\mathrm{CuSO}_{4} .5 \mathrm{H}_{2} \mathrm{O}$ $\mathrm{Al}$ system the slow reaction rate lowered the rate of displacement of $\mathrm{Cu}$.

The factors influencing the diffusion such as crystal structure and diffusivity of ions can also affect the kinetics. The reduction in water of hydration $\left(\mathrm{CuSO}_{4} \cdot \mathrm{H}_{2} \mathrm{O}\right)$ reduced the 
rate of displacement of $\mathrm{Cu}$ by $\mathrm{Fe}$ by several times though the driving force for the change was approximately the same as that in $\mathrm{CuSO}_{4} \cdot 5 \mathrm{H}_{2} \mathrm{O}-\mathrm{Fe}$ system. The open structure of $\mathrm{CuSO}_{4} .5 \mathrm{H}_{2} \mathrm{O}$ with channels aids faster diffusion. ${ }^{24}$ In contrast, the tightly packed threedimensional network of chemical bonds in the structure of $\mathrm{CuSO}_{4} \cdot \mathrm{H}_{2} \mathrm{O}^{25}$ implies a difficulty in the transport of $\mathrm{Cu}$ and $\mathrm{Fe}$. Even when the driving force for the displacement of copper is considerably lesser, the higher diffusivity of the metal like $\mathrm{Sn}$ through the crystal has resulted in extremely faster reaction rate in $\mathrm{CuSO}_{4} .5 \mathrm{H}_{2} \mathrm{O}-\mathrm{Sn}$ system (figure 9). Thus, apart from the effect of milling, the characteristics of the system also contribute significantly to the kinetics of milling induced changes.

\section{Physical properties of milled products}

\subsection{Magnetic properties of Finemet alloys}

The $\mathrm{Fe}-\mathrm{Cu}-\mathrm{Nb}-\mathrm{Si}-\mathrm{B}$ alloys (Finemet) are known for their attractive soft magnetic properties. The dispersion of nanocrystalline $\alpha \mathrm{Fe}(\mathrm{Si})$ phase in a residual amorphous

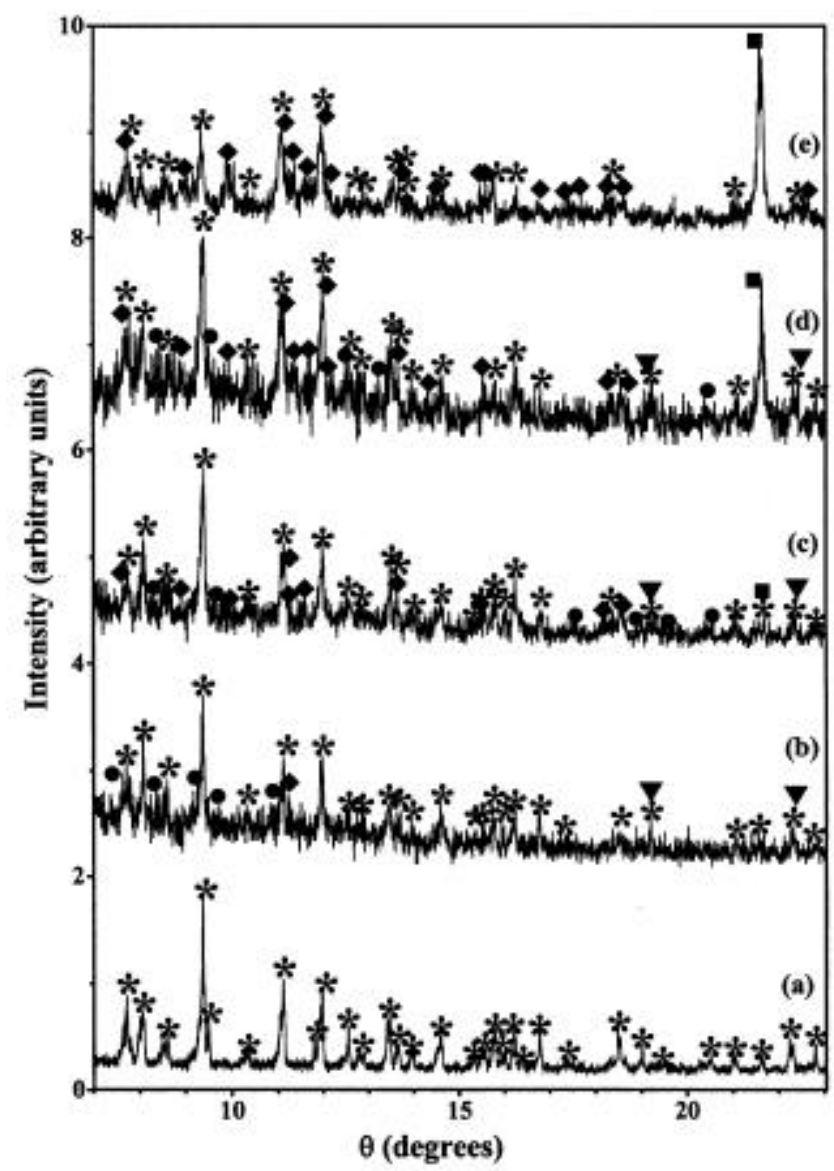

Figure 8. The X-ray diffraction patterns of (a) $\mathrm{CuSO}_{4} \cdot 5 \mathrm{H}_{2} \mathrm{O}$ powder, (b) $\mathrm{CuSO}_{4} .5 \mathrm{H}_{2} \mathrm{O}-\mathrm{Al}$ system after $3 \mathrm{~h}$, (c) $10 \mathrm{~h}$, (d) $20 \mathrm{~h}$ and (e) $75 \mathrm{~h}$, recorded using $\mathrm{Cu}_{\mathrm{K \alpha} 1} \cdot * \mathrm{CuSO}_{4} \cdot 5 \mathrm{H}_{2} \mathrm{O}, \boldsymbol{\nabla} \mathrm{Al}, \bigcirc$ intermediate, $\mathrm{Al}(\mathrm{OH}) \mathrm{SO}_{4} \cdot 5 \mathrm{H}_{2} \mathrm{O}$, and $\mathbf{C u}$. 


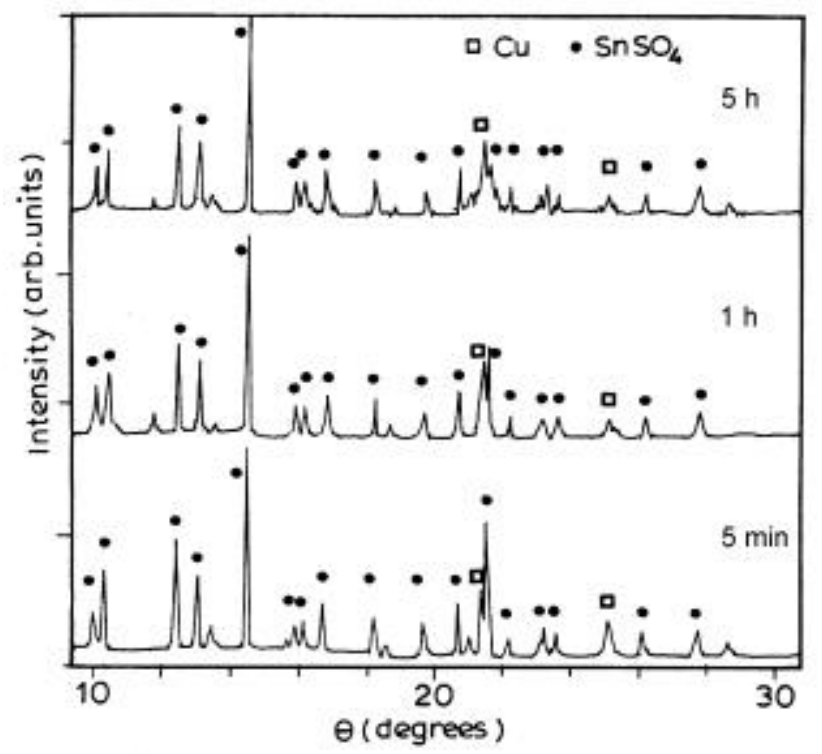

Figure 9. A series of $\mathrm{X}$-ray diffraction patterns as a function of milling time in the solid mixture of $\mathrm{Sn}$ and $\mathrm{CuSO}_{4} .5 \mathrm{H}_{2} \mathrm{O}$. Reaction is complete within five minutes.

matrix reduces the effective magnetic anisotropy and magnetostriction in the Finemet alloys. Thus, the soft magnetic property of the alloy arises from its characteristic microstructure. The microstructural dependence of the magnetic properties was explained by random anisotropy model (RAM) proposed for amorphous ferromagnets by Alben et $a .^{26}$

Minor addition of $\mathrm{Cu}$ to the conventional $\mathrm{Fe}-\mathrm{Si}-\mathrm{B}$ acts as nucleating agent while minor addition of $\mathrm{Nb}$ inhibits the grain growth of FeSi phase that crystallizes from the amorphous phase during annealing. The $\mathrm{Fe}-\mathrm{Si}-\mathrm{B}$ alloy loses its soft magnetic properties when it is completely crystallized while a controlled precipitation of the nanocrystalline state from the amorphous phase improves the property. The Finemet alloy with a desirable microstructure can be prepared by the melt-spinning technique followed by the annealing at elevated temperatures. We have analysed the role of magnetic interactions between the nanocrystalline and the residual amorphous phase by comparing the alloy produced by both melt spinning and mechanical alloying. ${ }^{8}$

Typical X-ray diffraction patterns of alloys produced by mechanical alloying (milled for $60 \mathrm{~h}$ ), melt spinning as well as annealed melt spun ribbon are given in figure 10 . The analysis clearly shows that the melt spun ribbons are completely amorphous while, only the nanocrystalline $\alpha \in \mathrm{Fe}(\mathrm{Si})$ phase is formed from the elemental powders during ball milling. The melt-spun alloy after heat treatment at $550^{\circ} \mathrm{C}$ for $1 \mathrm{~h}$ has both nanocrystalline phase and residual amorphous phase.

Figure 11 shows the thermomagnetic curves of mechanically alloyed and melt-spun Finemet alloys. From these curves, one can conclude that the magnetization of the meltspun amorphous ribbon is more stable against temperature than mechanically alloyed sample. The magnetization of melt-spun ribbon abruptly decreases to zero at $354^{\circ} \mathrm{C}$, which is the Curie temperature of the as quenched ribbon. The ribbon changes from 
ferromagnetic to paramagnetic state at $354^{\circ} \mathrm{C}$ and it remains paramagnetic up to $500^{\circ} \mathrm{C}$. The magnetization abruptly increases at $510^{\circ} \mathrm{C}$ followed by a decrease towards zero at $590^{\circ} \mathrm{C}$. The increase corresponds to the crystallization of the $\alpha \mathrm{FeSi}$ phase from the amorphous matrix, which is also supported by the microstructural studies of the meltspun ribbons using TEM. The transition at $590^{\circ} \mathrm{C}$ is the Curie temperature of $\alpha \mathrm{FeSi}$.

The coercivity of mechanically alloyed samples are two orders of magnitude larger than that of the annealed melt spun ribbon. ${ }^{8}$ The higher coercivity of the mechanically alloyed samples may be arising either from the internal strain developed during the process or the absence of grain boundary amorphous phase. To clarify, the samples were annealed in $\mathrm{H}_{2}$ atmosphere at 300,400 , and $550^{\circ} \mathrm{C}$ for $1 \mathrm{~h}$ and the magnetic properties

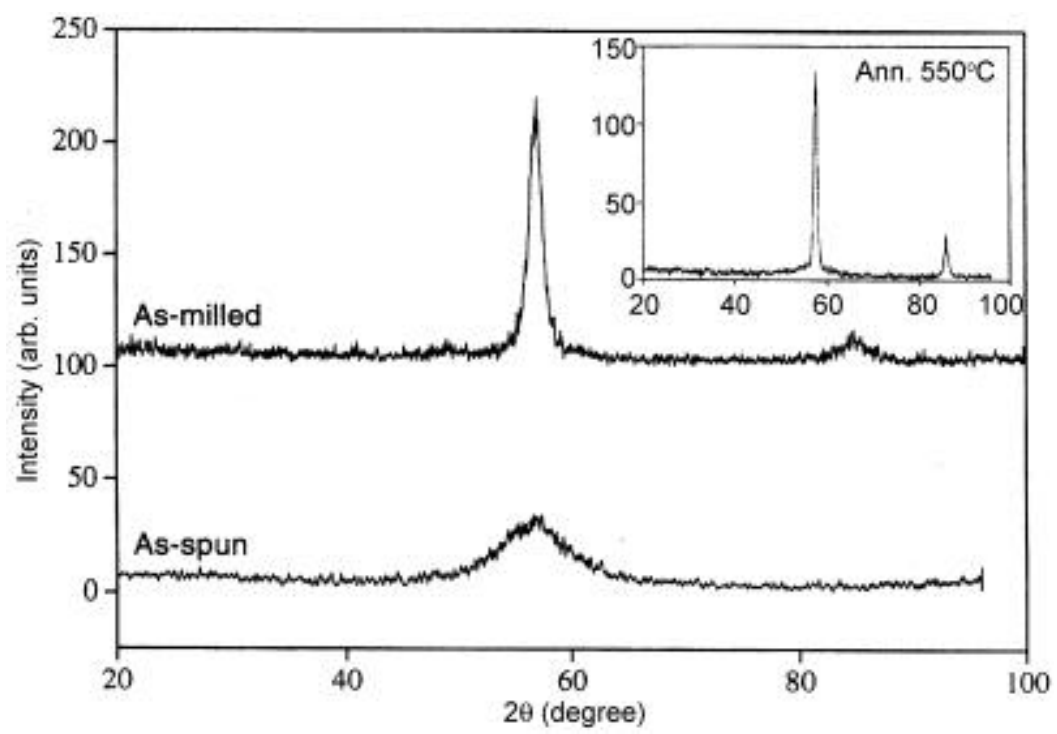

Figure 10. Typical XRD patterns of finemet alloys produced by mechanical alloying (milled for $60 \mathrm{~h}$ ), melt spinning as well as annealed melt spun ribbon.

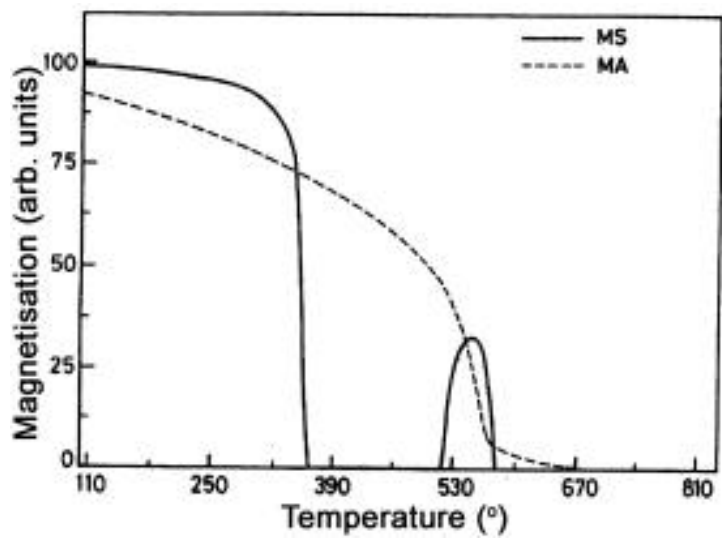

Figure 11. The thermomagnetic curves of mechanically alloyed and melt-spun finemet alloys. 
were measured. The strain analysis before and after heat treatment proved that there is significant reduction in the strain level after the heat treatment. However, the coercivity of the samples was found to increase. This indicates that the presence of the amorphous phase enhances the ferromagnetic exchange interaction between $\alpha \mathrm{FeSi}$ nanograins in the suitably annealed melt spun ribbon whereas the absence of amorphous phase weakens the interaction in the mechanically alloyed sample. Hence the magnetic softness of the mechanically alloyed samples is inferior to that of processed melt spun ribbons.

\subsection{Magnetic hardening in $\mathrm{Nd}_{2} \mathrm{Fe}_{14} \mathrm{~B}$}

$\mathrm{Nd}_{2} \mathrm{Fe}_{14} \mathrm{~B}$ is one of the hard magnetic phases with a wide variety of applications, which also plays a crucial role in the development of exchange spring magnets. The coercivity of the phase decreases when the grain size is smaller than the critical size of single domain due to coupling of the neighbouring grains by exchange interaction. The development of nanocrystalline two-phase magnets (exchange spring magnets), involving $\mathrm{Nd}_{2} \mathrm{Fe}_{14} \mathrm{~B}$ utilizes the high coercivity of the hard magnetic phase together with the easy magnetization of the soft phase. The optimum performance is obtained when the grain size of the hard phase is smaller than the single domain size. Though the coercivity of the exchange spring magnet is lesser than that of the hard phase, it has the potential to be cost effective. The coercivity is also affected by the grain size of the soft phase. The effect of alloying additions in controlling the coercive behaviour of $\mathrm{Nd}_{2} \mathrm{Fe}_{14} \mathrm{~B}$ is studied with $0 \cdot 1 \%$ $\mathrm{Cr}, \mathrm{Cu}$ and $\mathrm{Zr}^{9}$ Magnetically they correspond to antiferromagnetic, diamagnetic and paramagnetic impurities at room temperature.

Figure 12 shows the X-ray diffraction patterns of the prealloyed, milled and heat treated milled samples. Clearly milling induces amorphisation in the material. Heat treatment for $1.80 \mathrm{kS}$ at $823 \mathrm{~K}$ crystallizes the $\mathrm{Nd}_{2} \mathrm{Fe}_{14} \mathrm{~B}$ in the nano-range. The milled samples with additives after heat treatment are identical indicating that the additives do not have any effect on the formation of $\mathrm{Nd}_{2} \mathrm{Fe}_{14} \mathrm{~B}$. The average grain size in these cases

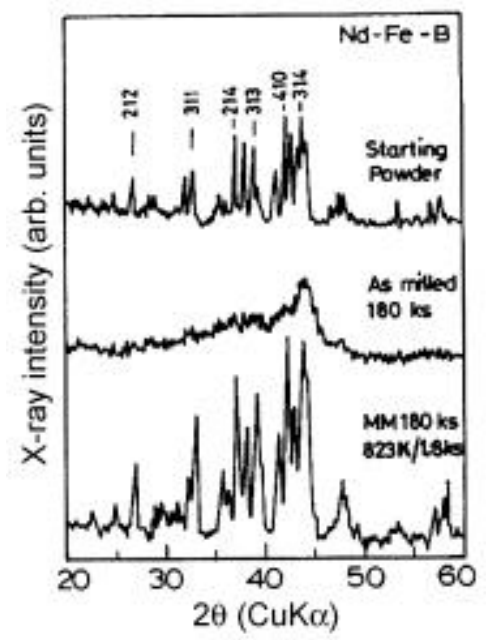

Figure 12. The X-ray diffraction patterns of the prealloyed, milled and heat-treated milled samples of $\mathrm{Nd}_{2} \mathrm{Fe}_{14} \mathrm{~B}$ in the nano range. 
was found to be $22 \mathrm{~nm}$. The influence of the small amount of additives on the coercivity in nanograined single domain $\mathrm{Nd}_{2} \mathrm{Fe}_{14} \mathrm{~B}$ materials prepared by mechanical alloying is also studied. Figure 13 shows the variation in coercivity as a function of the applied field for the four samples. Both $\mathrm{Cu}$ and $\mathrm{Cr}$ addition enhances the coercivity while $\mathrm{Zr}$ addition decreases the coercivity. The study concludes with further evidence that the mechanism of magnetic hardening in nanocrystalline $\mathrm{Nd}_{2} \mathrm{Fe}_{14} \mathrm{~B}$ is mostly pinning type proving the importance of the location of impurities in deciding the hardening mechanism.

\subsection{Thermoelectric properties of $\mathrm{Cu}-\mathrm{Te}$ alloys}

Tellurides are attractive materials for thermoelectric applications due to their very high thermopower values and ability to yield both $p$ and $n$ type materials by doping. An improvement of the efficiency of these materials for thermoelectric applications is possible by microstructural control involving grain size reduction. Since a major part of thermal conductivity is controlled by phonon conduction, introduction of a large amount of grain boundaries can lead to scattering and significant decrease in the conductivity. Thus mechanical alloying becomes a potential choice for synthesizing thermoelectric materials. We have investigated the effect of milling on synthesis of $\mathrm{Cu}_{2} \mathrm{Te}$ as well as the thermoelectric properties. ${ }^{15}$

XRD patterns (figure 14) show that after $6 \mathrm{~h}$ of milling, $\mathrm{Cu}_{2} \mathrm{Te}$ becomes the prominent phase. Although there exists a large number of phases near the $\mathrm{Cu}_{2} \mathrm{Te}$ composition, the observed lines are best fitted with a phase corresponding to hexagonal structure $P 6 / \mathrm{mmm}$ with $a=0.8328 \mathrm{~nm}$ and $c=0.7319 \mathrm{~nm}$. The average grain size reduced quickly in the initial hours and stabilized at $10 \mathrm{~nm}$ after $40 \mathrm{~h}$. Samples obtained from grinding of prealloyed samples through melting are not significantly different.

The thermopower of the as-cast sample was found to be $37.4 \mu \mathrm{V}$ per $\mathrm{K}$, much higher than the reported value for $\mathrm{Cu}_{2} \mathrm{Te}^{27}$ The discrepancy may be due to the existence of several crystal structures for $\mathrm{Cu}_{2}$ Te. Figure 15 shows the thermo power against milling time for two different compaction pressures. Clearly the thermopower of the mechanically alloyed samples approached the bulk value with long milling times. Higher consolidation pressure showed a quick increase in thermopower within 10-22.5 h while

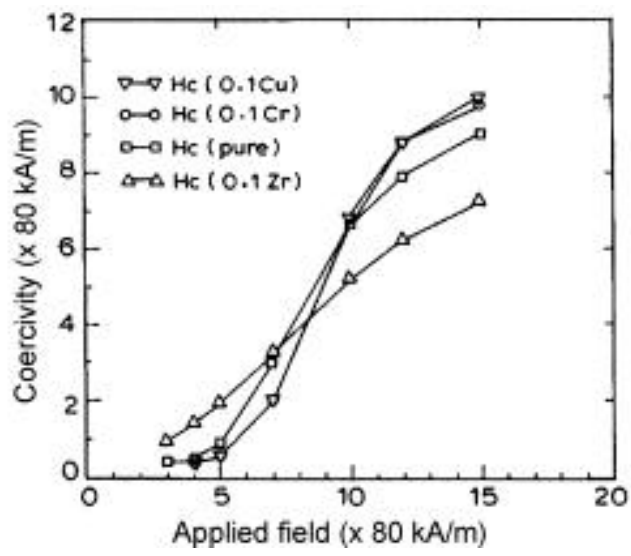

Figure 13. The variation in coercivity as a function of the applied field for the four samples. 


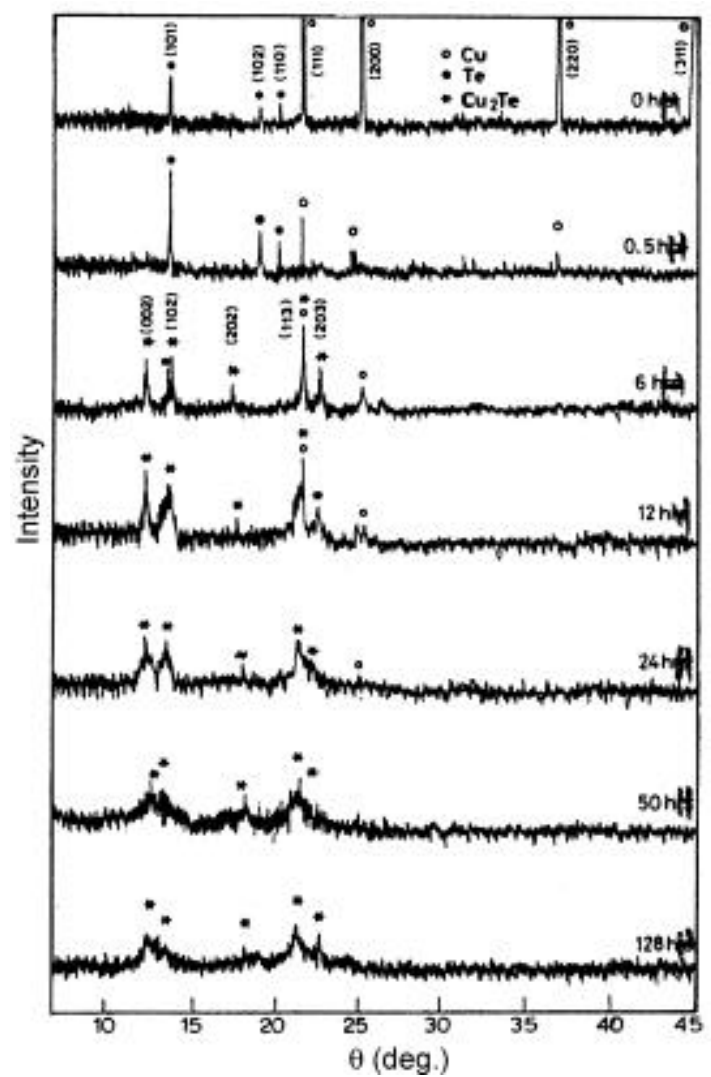

Figure 14. The $\mathrm{X}$-ray diffraction patterns of $\mathrm{Cu}-\mathrm{Te}$ system as a function of milling time.

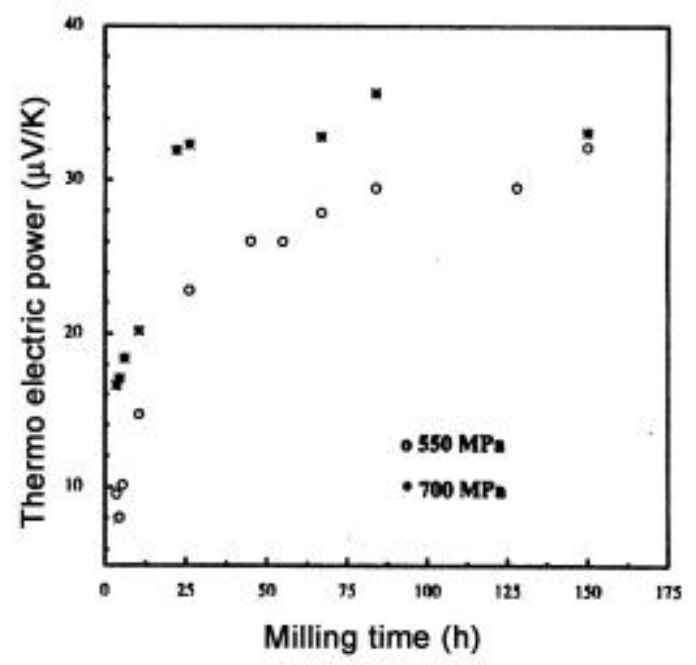

Figure 15. The variation in thermopower against milling time for two different compaction pressures. 
the $\mathrm{Cu}_{2} \mathrm{Te}$ was forming. However, the melted and ground samples also shows a gradual increase to bulk value indicating the importance of longer milling time.

\section{Concluding remarks}

The examples cited above clearly point to the usefulness of studying the effects of mechanical energy on simple systems. Such studies enrich our understanding about the process and properties of the resultant products. An increasing understanding of these may allow us to explore new possibilities for mechanical alloying and the mechanochemical reactions.

\section{Acknowledgements}

The authors acknowledge the contribution of their coworkers, Drs M Manivel Raja, K Raviprasad, Chitralekha Jacob, Bhaskar Majumdar, Joyita De, K Sreedhar and Mainak Biswas for some of the work mentioned in this article. Financial support from the Department of Science and Technology, Govt. of India and Council of Scientific and Industrial Research, New Delhi is gratefully acknowledged.

\section{References}

1. Benjamin J S 1976 Sci. Am. 23440

2. Murthy B S and Ranganathan S 1998 Int. Mater. Rev. 43101

3. Suryanarayana C 2001 Progr. Mater. Sci. 461

4. Ding J, Tsuzuki T and McCormick P G 1996 J. Am. Ceram. Soc. 792956

5. Schaffer G B and McCormick P G 1989 J. Appl. Phys. Lett. 5545

6. Takacs L 2002 Progr. Mat. Sci. 46355

7. Takacs L 2000 J. Mater. Miner. Met. 5212

8. Manivel Raja M, Chattopadhyay K, Majumdar B and Narayanasamy A 2000 J. Alloys Compounds 297199

9. Raviprasad K, Ravishankar N, Chattopadhyay K and Umemoto M 1998 J. Appl. Phys. 83916

10. Chitralekha J, Raviprasad K, Gopal E S R and Chattopadhyay K 1995 J.Mater. Res. 101897

11. Majumdar B, Manivel Raja M, Narayanasamy A and Chattopadhyay K 1997 J. Alloys Compounds 248192

12. Ravishankar N, Abinandanan T A and Chattopadhyay K 2001 Mater. Sci. Eng. A304-306 413

13. Varghese V, Sharma A and Chattopadhyay K 2001 Mater. Sci. Eng. A304-306 434

14. Biswas M, Varghese V and Chattopadhyay K 2002 (unpublished work)

15. Sridhar K and Chattopadhyay K 1998 J. Alloys Compounds 264293

16. Luo H L and Klement W J 1962 J. Chem. Phys. 361870

17. Parthasarathy G and Holzapfel W B 1988 Phys. Rev. B37 8499

18. Tian H H and Atzmon M 1999 Acta Mater. 471255

19. Koch C C 1995 Mater. Trans. Jpn. Inst. Met. 3685

20. Majumder B 1996 Thermodynamics and microstructural development in immiscible systems processed through different routes, $\mathrm{Ph} \mathrm{D}$ thesis, Indian Institute of Science, Bangalore

21. Martin G and Bellon P 1997 Solid State Phys. 50189

22. Uenishi K, Kobayashi K F, Ishihara K N and Shingu P H 1991 Mater. Sci. Eng. A134 1342

23. Herr U and Samwer K 1994 In Solid state phase transformations (eds) W C Johnson, J W Howe, D E Laughlin and W A Soffa (Warrendale: TMS) p. 1039

24. Baur W H and Rolin J L 1972 Acta Crystallogr. B28 1448

25. Ferguson G and Trotter J (eds) 1988 Structure reports (Metals and Inorganic Sections), International Union of Crystallography (Dordrecht: Kluwer Academic Publishers) vol 55A

26. Alben R, Becker J J and Chi M C 1996 J. Appl. Phys. 805209

27. Okhotin A S and Pushkarasky A S 1976 In Proc. Int. Conf. on Thermoelectric Energy Conversion (ed.) K R Rao (New York: IEEE) 